Fetal Diagnosis aur Therapy
Fetal Diagn Ther 2019;45:162-167

DOI: $10.1159 / 000488486$
Received: February 21, 2018

Accepted after revision: March 15, 2018

Published online: May 7, 2018

\title{
Long-Term Neurodevelopmental and Respiratory Outcome after Intrauterine Therapy for Fetal Thoracic Abnormalities
}

\author{
Ruben S.G.M. Witlox ${ }^{\mathrm{a}}$ Enrico Lopriore ${ }^{\mathrm{a}}$ Monique Rijken $^{\mathrm{a}}$ \\ Frans J.C.M. Klumper ${ }^{\mathrm{b}}$ Dick Oepkes ${ }^{\mathrm{b}}$ Jeanine M.M. van Klink ${ }^{\mathrm{a}}$ \\ aDivision of Neonatology, Department of Pediatrics, Leiden University Medical Center, Leiden, The Netherlands; \\ ${ }^{b}$ Division of Fetal Therapy, Department of Obstetrics, Leiden University Medical Center, Leiden, The Netherlands
}

\begin{abstract}
Keywords
Fetal pleural effusion - Congenital cystic adenomatoid malformation - Bronchopulmonary sequestration .

Thoracoamniotic shunt · Fetal therapy · Developmental outcome
\end{abstract}

\begin{abstract}
Introduction: The aim of this study is to evaluate long-term neurodevelopmental and respiratory outcome after fetal therapy for fetal pleural effusion, congenital cystic adenomatoid malformation, and bronchopulmonary sequestration. Methods: Children $\geq 18$ months of age underwent an assessment of neurologic, motor, and cognitive development. Medical records were reviewed to determine respiratory outcome. Behavioral outcome was assessed using the Child Behavioral Checklist. Results: Between 2001 and 2016, 63 fetuses with fetal hydrops secondary to thoracic abnormalities were treated at our center. Overall perinatal survival was $64 \%(40 / 63)$. Twenty-six children were included for follow-up (median age 55 months). Severe neurodevelopmental impairment (NDI) was detected in 15\% (4/26). Three out of 4 children with severe NDI had associated causes contributing to the impairment. Overall adverse outcome, including perinatal mortality or NDI, was 55\% (27/49). Fifteen percent
\end{abstract}

(4/26) had severe respiratory sequelae. Parents did not report more behavioral problems than Dutch norms. Discussion: Our results suggest that severe NDI in this specific highrisk cohort occurs in 15\%, which is above the range of the incidence of NDI reported in case series treated with other fetal therapies (5-10\%). Large multicenter studies and an international web-based registry are warranted to prospectively gather outcome data at fixed time points.

(C) 2018 The Author(s)

Published by S. Karger AG, Basel

\section{Introduction}

Congenital thoracic abnormalities present in different forms prenatally. Fetal pleural effusion (FPE) presents as pleural fluid on prenatal ultrasound, probably due to leakage of lymphatic fluid in the pleural space $[1,2]$. Congenital cystic (or pulmonary) adenomatoid malformation (CCAM) and bronchopulmonary sequestration (BPS) present as cystic or solid lung masses. CCAMs are classified as microcystic or macrocystic based on ultrasound appearance [3]. A BPS is a solid lung mass characterized by an arterial feeding vessel originating from the systemic vasculature.

\begin{tabular}{ll}
\hline KARGER & $\begin{array}{l}\text { ( } 2018 \text { The Author(s) } \\
\text { Published by S. Karger AG, Basel }\end{array}$ \\
E-Mail karger@karger.com & $\begin{array}{l}\text { This article is licensed under the Creative Commons Attribution- } \\
\text { NonCommercial-NoDerivatives 4.0 International License (CC BY- } \\
\text { NC-ND) (http://www.karger.com/Services/OpenAccessLicense). } \\
\text { Usage and distribution for commercial purposes as well as any dis- } \\
\text { tribution of modified material requires written permission. }\end{array}$
\end{tabular}

Jeanine M.M. van Klink, $\mathrm{PhD}$

Department of Pediatrics, J6-S, Leiden University Medical Center PO Box 9600

NL-2300 RC Leiden (The Netherlands)

E-Mail j.m.m.van_klink@lumc.nl 
The outcome in FPE, CCAM, and BPS is heterogeneous and varies from spontaneous resolution to severe fetal hydrops and perinatal death. Perinatal outcome is particularly poor in cases complicated by severe fetal hydrops. Perinatal survival rate in hydropic fetuses with FPE or CCAM ranges from 5 to 30\% [4-8]. Prenatal fetal intervention is primarily indicated in cases with fetal hydrops and is associated with an increased survival rate of up to $65 \%[4,7]$. Fetal intervention for these lesions is aimed at permanently reducing the space-occupying effect of the lesion and includes thoracoamniotic shunt placement in FPE, macrocystic CCAM, and BPS with pleural effusion [8-10]. BPS can also be treated by laser coagulation of the feeding vessel [11].

One of the concerns of the successful use of fetal therapy is that an increase in perinatal survival may be associated with an increase in children with long-term handicaps. Long-term follow-up studies are lacking and counseling of parents prior to fetal interventions is limited to information on perinatal survival.

The aim of this study is to report on the long-term neurodevelopmental, behavioral, and respiratory outcome after fetal therapy for congenital thoracic abnormalities including FPE, CCAM, and BPS.

\section{Methods}

In this observational cohort study, we included all patients with FPE, CCAM, or BPS treated with thoracoamniotic shunting or laser coagulation of the feeding vessel of BPS at our center between January 2001 and May 2016. The Leiden University Medical Center (LUMC) is the national referral center for invasive fetal therapy in the Netherlands. Patients throughout the Netherlands are referred to our center for these therapies.

The indication for fetal therapy was hydrops, defined as an accumulation of fluid in two or more compartments, including pleural effusion, skin edema, ascites, and/or pericardial effusion. For the purpose of this study, we invited all families with their surviving children of at least 18 months of age (corrected for prematurity) to participate in this follow-up study. The study was approved by the ethics committee of the LUMC. Informed consent was obtained from all participating families.

A follow-up visit included a neurologic examination according to Touwen et al. [12] and an assessment of cognitive and motor development using the Bayley Scales of Infant and Toddler Development (Bayley-III) in children between 18 and 36 months of age [13]. Cognitive development of children between 3 and 7 years of age was tested with the Wechsler Preschool Primary Scale of Intelligence (WPPSI-III) [14]. Children at the age of $\geq 7$ years were tested with the Wechsler Intelligence Scale for Children (WISC-III) [15]. Both the WPPSI and WISC provide a Total IQ (TIQ) score including a Verbal IQ (VIQ) and a Performance IQ (PIQ). Bayley, WPPSI, and WISC scores follow a normal distribution curve with a normed mean of 100 and a standard deviation (SD) of 15 . A test

Long-Term Outcome after Fetal Therapy

for Thoracic Abnormalities score, that is, a Bayley-III cognitive or motor score, WPPSI and WISC TIQ, VIQ, or PIQ score, below $70(<-2$ SD) indicates severe delay. Scores below $85(<-1 \mathrm{SD})$ indicate mild-to-moderate delay. Children who could not be tested due to severe cognitive impairment were assigned a nominal score of 49 to reflect severe developmental delay. A trained psychologist (J.M.M.v.K.) performed the psychometric tests in all children.

Cerebral palsy was defined according to the European CP Network and classified as spastic bilateral, spastic unilateral, dyskinetic (dystonic or choreo-athetotic), ataxic, or mixed [16]. Severity was classified according to the Gross Motor Function Classification System (GMFCS) for Cerebral Palsy [17]. Minor neurological dysfunction (MND) was defined as a moderate abnormality of tone, posture, and movement leading to only minor functional impairment or minor developmental delay [12].

The Achenbach's Child Behavior Checklist (CBCL) versions $1 \frac{1 / 2-5}{2}$ and $6-18$ years $[18,19]$ was used to measure the occurrence of problem behavior. For the purpose of this study, the Total problem scale and the two syndrome scales Internalizing (withdrawn, somatic complaints, anxious/depressed) and Externalizing (delinquent or rule-breaking, aggressive) behavior problems were used. $\mathrm{T}$ scores were computed from raw scores with higher scores indicating greater severity of problems. T scores of the normative sample have a mean of $50 \pm$ SD 10 . A clinical score in $10 \%$ of the children for the Total, Internalizing, and Externalizing behavior problem scales ( $\mathrm{T}$ score $\geq 64$ ) served as cut-off points for comparison with Dutch normative data [19].

The primary outcome measure was a composite outcome termed severe neurodevelopmental impairment (NDI) including cerebral palsy (GMFCS II-V), cognitive or motor test score $<70$, bilateral blindness, or bilateral deafness requiring amplification. Mild-to-moderate impairment was defined as MND, a cognitive or motor test score $<85$, mild hearing impairment, or mild visual impairment with good functional vision when corrected with glasses. An "overall adverse outcome" was calculated including perinatal mortality or severe NDI. Secondary outcomes included behavioral problem scores and respiratory outcome, including discharge on home oxygen and hospital readmissions for respiratory problems in the first 24 months after birth.

\section{Statistical Analysis}

All data were analyzed using SPSS version 20.0 (IBM, Armonk, NY, USA). Categorical data are presented as numbers and percentages and continuous variables are presented as median with interquartile range (IQR) and/or range. The percentages of children with a clinical CBCL score (T score $\geq 64$ ) were compared with normative percentages ( $10 \%$ with clinical score) using a binomial test. The level of statistical significance for all analyses was set at $p<$ 0.05 .

\section{Results}

In the study period, 63 fetuses with thoracic abnormalities and hydrops were treated antenatally. The antenatal and neonatal outcome of the 48 fetuses with FPE has been described earlier [20]. A flowchart showing the derivation of all patients is shown in Figure 1. 


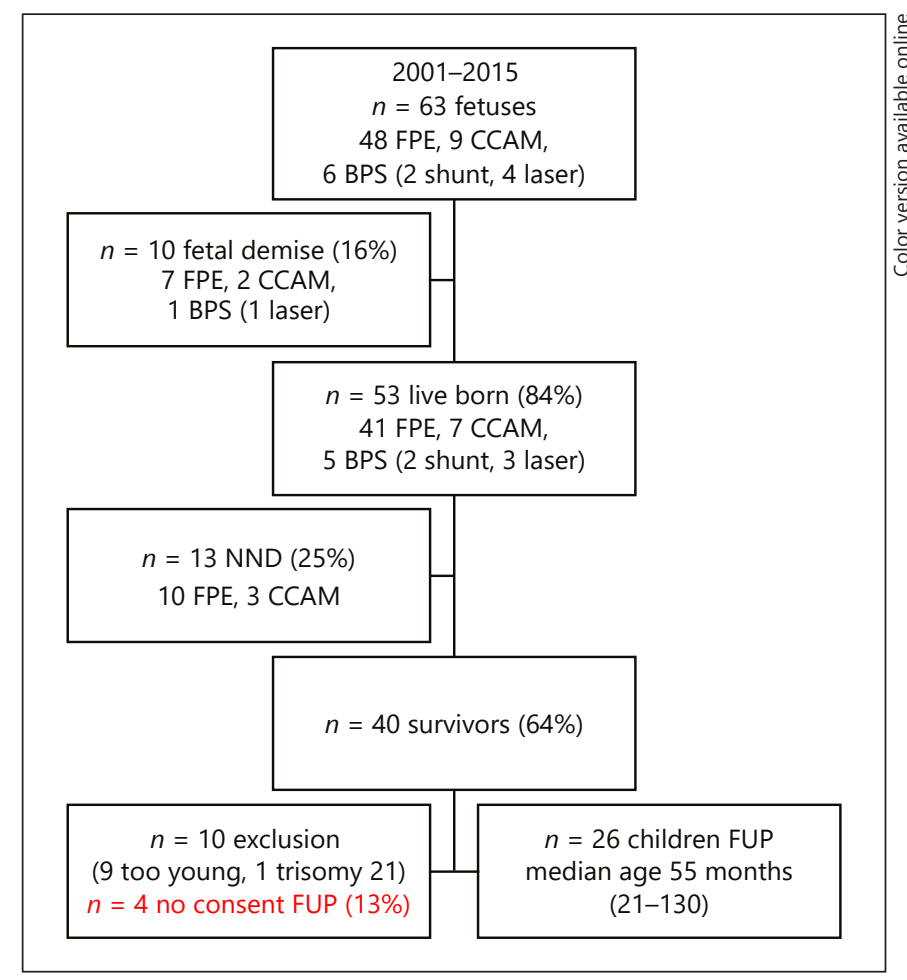

Fig. 1. Flowchart showing the derivation of the study population. FPE, fetal pleural effusion; CCAM, cystic adenomatoid malformation; BPS, bronchopulmonary sequestration; NND, neonatal death; FUP, follow-up.

Median gestational age at shunt placement or laser coagulation was 28.0 weeks (IQR 22.9-30.8 weeks). Fetal demise occurred in $16 \%(10 / 63)$ of pregnancies after the intervention. Eighty-four percent (53/63) of neonates were live born at a median gestational age of 33.9 weeks (IQR 30.5-36.5 weeks). Thirty percent (16/53) of liveborn neonates were born very preterm, below a gestational age of 32 weeks. Seventy-five percent (40/53) of live-born fetuses survived the neonatal period. Overall perinatal survival was $64 \%(40 / 63)$. Perinatal survival was $63 \%(31 / 48)$ in fetuses with FPE, 44\% (4/9) in fetuses with CCAM, and $83 \%(5 / 6)$ in fetuses with BPS.

\section{Neurodevelopmental Outcome}

Twenty-six children were included for long-term follow-up at a median age of 55 months (range 21-130). Detailed information on the results can be found in Tables $1-3$. The overall incidence of severe NDI in the children included for follow-up was $15 \%$ (4/26). For the "overall adverse outcome" assessment, 49 fetuses were included. From the 63 fetuses that were treated antenatally, 10 chil- dren were excluded from analysis and in 4 cases (13\%), parents gave no consent for testing (Fig. 1). Overall adverse outcome, including perinatal mortality (fetal demise $[n=10]$ and neonatal death $[n=13])$ or long-term NDI $(n=4)$, was $27 / 49$ (55\%).

Severe cognitive development, a score $<70$, was detected in $12 \%(3 / 26)$ of children and mild-to-moderate cognitive development, a score $<85$, in $15 \%(4 / 26)$. Median cognitive score was 105 (range: 58-120), 102 (range: 86118 ), and 87 (range: $47-103$ ) according to Bayley-III ( $n=$ $8)$, WPPSI-III $(n=9)$, and WISC-III $(n=8)$ assessment, respectively. Overall median cognitive score was 95 (range: 47-120). One child (case No. 15) had severe cognitive impairment and severe motor dysfunction due to congenital hypomyelinating neuropathy. She could not be assessed with formal psychometric testing and was assigned a test score of 49 in the database. Another child (case No. 19) moved with her family to another country where pediatric examinations showed age-appropriate motor and cognitive development. No score, that is, a missing value, was assigned in the database. Nineteen percent $(5 / 26)$ of children had mild motor dysfunction according to Touwen examination.

After birth, two children (cases No. 1 and 19) were diagnosed with Noonan syndrome. Case No. 1 presented with normal neurodevelopmental outcome at follow-up at the age of 6 years (WISC TIQ 96) and attends a regular school. Case No. 19 presented with severe cognitive and motor impairment at follow-up at 23 months of age. A tracheostomy has been placed due to severe respiratory failure probably because of congenital pulmonary lymphangiectasia (CPL) and a percutaneous endoscopic gastrostomy was performed to maintain nutrition. Recent ventilation tube insertion for both ears has resulted in better hearing, that is, from a hearing loss of approximately 80 decibels to a loss of less than 20-50 decibels. He attends a medical daycare facility. Twenty-seven percent (7/26) of children had mild visual impairment with good functional vision when corrected with glasses. Mild-tomoderate impairment, including MND, test scores below 85 , and mild hearing and/or visual impairments, was present in $25 \%(9 / 26)$ of survivors.

\section{Behavioral Outcome}

Complete behavioral questionnaires were obtained from the parents of $85 \%(22 / 26)$ of children $(n=1 \leq 18$ months of age and $n=4$ questionnaires not returned). According to the CBCL $1 \frac{1}{2}-5(n=13)$, mean Total problem score was $48.4 \pm 12.2$. Mean Internalizing and Externalizing problem scores were $46.6 \pm 15.1$ and $50.5 \pm 10.0$, 
Table 1. Perinatal and long-term outcome of 20 cases of fetal pleural effusion treated with thoracoamniotic shunt placement

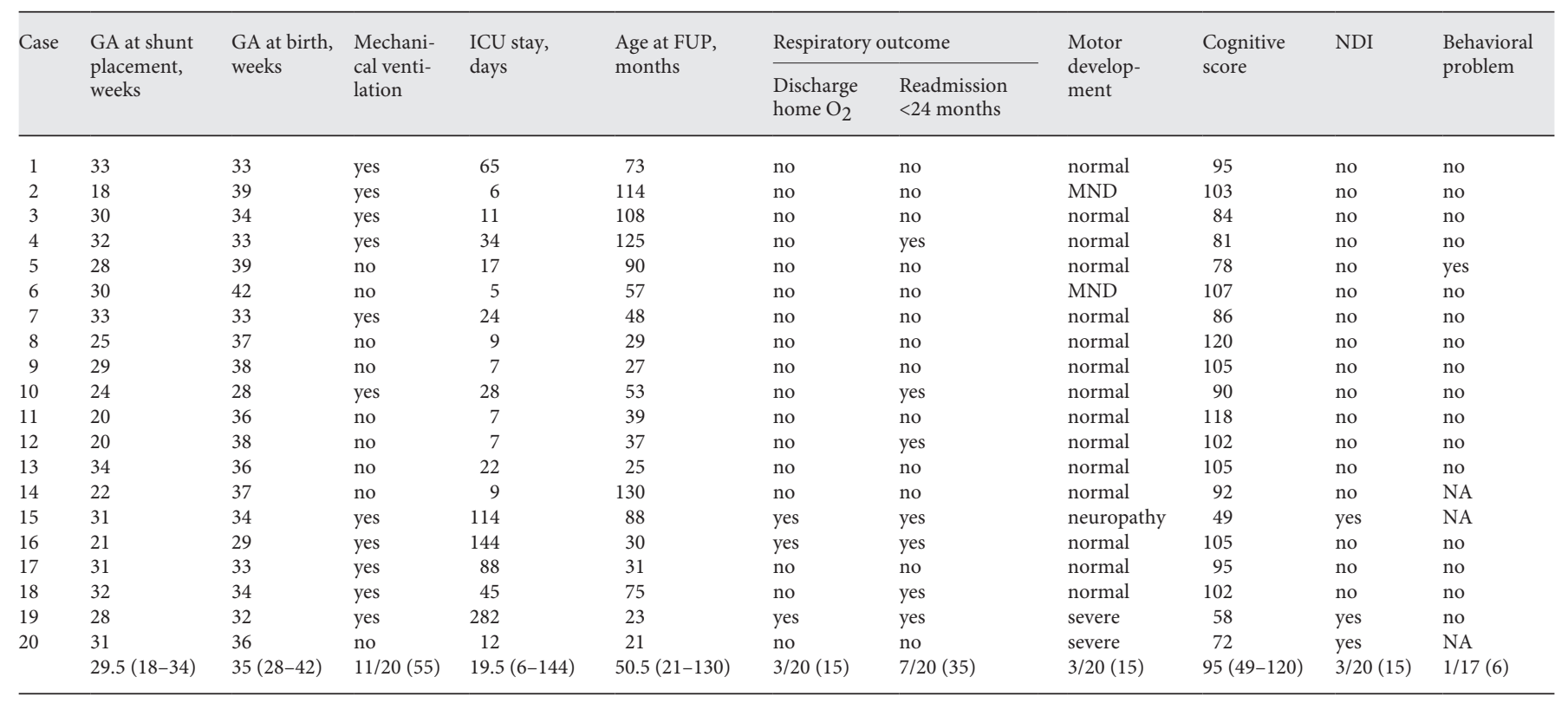

Data are summarized as median (range) or $n / N$ (percentage). GA, gestational age; ICU, intensive care unit; FUP, follow-up; NDI, neurodevelopmental impairment; MND, minor neurologic dysfunction; NA, not assessed.

Table 2. Perinatal and long-term outcome of 4 cases of bronchopulmonary sequestration treated with fetal therapy

\begin{tabular}{|c|c|c|c|c|c|c|c|c|c|c|c|c|c|}
\hline Case & $\begin{array}{l}\text { Indica- } \\
\text { tion }\end{array}$ & Therapy & $\begin{array}{l}\text { GA at } \\
\text { therapy, } \\
\text { weeks }\end{array}$ & $\begin{array}{l}\text { GA at birth, } \\
\text { weeks }\end{array}$ & $\begin{array}{l}\text { Mechan- } \\
\text { ical } \\
\text { ventila- } \\
\text { tion }\end{array}$ & $\begin{array}{l}\text { ICU stay, } \\
\text { days }\end{array}$ & $\begin{array}{l}\text { Age at FUP, } \\
\text { months }\end{array}$ & \multicolumn{2}{|c|}{ Respiratory outcome } & $\begin{array}{l}\text { Motor } \\
\text { develop- } \\
\text { ment }\end{array}$ & $\begin{array}{l}\text { Cognitive } \\
\text { score }\end{array}$ & NDI & $\begin{array}{l}\text { Behav- } \\
\text { ioral } \\
\text { problem }\end{array}$ \\
\hline 22 & BPS & laser & 23 & 39 & no & 3 & 110 & no & yes & normal & 102 & no & no \\
\hline 23 & BPS & laser & 29 & 41 & no & 0 & 61 & no & no & normal & 90 & no & no \\
\hline 24 & BPS & laser & 25 & 38 & no & 4 & 48 & no & no & normal & NA & no & NA \\
\hline
\end{tabular}

Data are summarized as median (range) or $n / N$ (percentage). GA, gestational age; ICU, intensive care unit; FUP, follow-up; NDI, neurodevelopmental impairment; BPS, bronchopulmonary sequestration; NA, not assessed

respectively. According to the CBCL 6-18 $(n=9)$, mean scores were $56.67 \pm 9.1,51.4 \pm 11.4$, and $53.0 \pm 11.8$, respectively. T scores of the normative sample have a mean of $50 \pm 10$. Overall, behavioral problems within the clinical range were reported in $9 \%(2 / 22)$ of cases, with internalizing problems in $9 \%(2 / 22)$ and externalizing problems in $9 \%(2 / 22)$ of cases. No differences compared with normative percentages $(10 \%$ with clinical score, Dutch norm population) were reported $(p>0.05)$.

Long-Term Outcome after Fetal Therapy for Thoracic Abnormalities

\section{Respiratory Outcome}

Fifteen percent (4/26) of children still received oxygen therapy at discharge from the hospital. One child (case No. 15) was born at 29 weeks' gestation and was diagnosed with a severe neuropathy. One child (case No. 19) was diagnosed with Noonan syndrome after birth and appeared to suffer from CPL requiring long-term ventilation through a tracheostomy. The two other children requiring home oxygen were born prematurely at a gestational age of 26 and 29 weeks. Thirty-one percent (8/26) 
Table 3. Perinatal and long-term outcome of 2 cases of congenital cystic adenomatoid malformation treated with thoracoamniotic shunt placement

\begin{tabular}{|c|c|c|c|c|c|c|c|c|c|c|c|c|c|}
\hline \multirow[t]{2}{*}{ Case } & \multirow{2}{*}{$\begin{array}{l}\text { Indica- } \\
\text { tion }\end{array}$} & \multirow[t]{2}{*}{ Therapy } & \multirow{2}{*}{$\begin{array}{l}\text { GA at } \\
\text { therapy, } \\
\text { weeks }\end{array}$} & \multirow{2}{*}{$\begin{array}{l}\text { GA at birth, } \\
\text { weeks }\end{array}$} & \multirow{2}{*}{$\begin{array}{l}\text { Mechan- } \\
\text { ical } \\
\text { ventila- } \\
\text { tion }\end{array}$} & \multirow{2}{*}{$\begin{array}{l}\text { ICU stay, } \\
\text { days }\end{array}$} & \multirow{2}{*}{$\begin{array}{l}\text { Age at FUP, } \\
\text { months }\end{array}$} & \multicolumn{2}{|c|}{ Respiratory outcome } & \multirow{2}{*}{$\begin{array}{l}\text { Motor } \\
\text { develop- } \\
\text { ment }\end{array}$} & \multirow{2}{*}{$\begin{array}{l}\text { Cognitive } \\
\text { score }\end{array}$} & \multirow[t]{2}{*}{ NDI } & \multirow{2}{*}{$\begin{array}{l}\text { Behav- } \\
\text { ioral } \\
\text { problem }\end{array}$} \\
\hline & & & & & & & & $\begin{array}{l}\text { discharge } \\
\text { home } \mathrm{O}_{2}\end{array}$ & $\begin{array}{l}\text { readmission } \\
<24 \text { months }\end{array}$ & & & & \\
\hline 25 & CCAM & shunt & 23 & 38 & no & 7 & 109 & no & no & MND & 89 & no & no \\
\hline \multirow[t]{2}{*}{26} & CCAM & shunt & 22 & 26 & yes & 98 & 123 & yes & no & MND & 47 & yes & no \\
\hline & & & $22.5(22-23)$ & $32(26-38)$ & $1 / 2(50)$ & $52.5(7-98)$ & $116(109-123)$ & $1 / 2(50)$ & $0 / 2(0)$ & $0 / 2(0)$ & $68(47-89)$ & $1 / 2(50)$ & $0 / 2(0)$ \\
\hline
\end{tabular}

Data are summarized as median (range) or $n / N$ (percentage). GA, gestational age; ICU, intensive care unit; FUP, follow-up; NDI, neurodevelopmental impairment; CCAM, congenital cystic adenomatoid malformation; MND, minor neurologic dysfunction.

of children were readmitted to the hospital for respiratory problems (mainly respiratory tract infections) after discharge home and within 24 months after birth.

\section{Discussion}

In this study, we evaluated the long-term outcome in survivors after fetal therapy for congenital thoracic abnormalities including FPE, CCAM, and BPS. Overall adverse outcome, including perinatal mortality or severe long-term impairment, was high (55\%) but was mainly due to a relative high risk of perinatal death. Severe NDI in long-term survivors was detected in 15\%. Mild-tomoderate impairment was present in $25 \%$ of survivors. Compared with Dutch normative data, the parents of the children did not report more behavioral problems.

This is the first detailed analysis of a relatively large cohort of long-term survivors after fetal interventions for FPE, CCAM, and BPS. We employed standardized psychometric tests in all children performed by a certified child psychologist. Importantly, the lost-to-follow-up rate was low (13\%), reducing the risk of selection bias. To date, only one long-term follow-up study of survivors after fetal intervention for congenital thoracic abnormalities has been published. Caserio et al. [7] reported on respiratory morbidity in a group of 15 survivors after congenital chylothorax. They found recurrent respiratory infections and signs of asthma in $27 \%$ of survivors. However, not all patients received fetal treatment, and some of the survivors were diagnosed with chylothorax only postnatally. In our study, we did not record the percentage of children with respiratory infections or signs of asthma as we think these parameters are not specific for respiratory problems in this selective population of children. However, some children (15\%) had severe respiratory sequel- ae, with the need of home oxygen therapy after hospital discharge. This appeared to be related to premature birth, CPL, and severe demyelinating neuropathy. Unfortunately, we do not have the facilities to perform lung function testing in children below the age of 5 years in our hospital. Lung function testing would have been a more objective measure to quantify respiratory outcome in this population.

Neurodevelopmental outcome in children treated with fetal therapy for pleural effusion or congenital thoracic abnormalities has not been reported before. Our results suggest that long-term NDI in this specific high-risk cohort occurs in $15 \%$ of survivors, which is above the range of the incidence of NDI reported in case series treated with other fetal therapies (5-10\%) [21-24]. The rate of NDI in children treated with intrauterine transfusion for alloimmune hemolytic disease was reported in $5 \%$ [21]. In children treated with fetoscopic laser surgery for twin-twin transfusion syndrome, long-term NDI occurs in 10\% in most recent series [25]. NDI has been reported in $7 \%$ of children treated with selective reduction in complicated monochorionic twin pregnancies [22]. In most studies, prematurity and severe neonatal morbidity were identified as potential risk factors for NDI. Unfortunately, in this study, the sample size was too small to perform a risk factor analysis which would allow results to be adjusted for, e.g., the underlying cause of hydrops and prematurity. In addition, three out of four children with severe NDI had associated causes contributing to the impairment, that is, hypomyelinating neuropathy, Noonan syndrome, and NAA10-gene mutation. These associated anomalies might therefore contribute more to this relatively high rate of NDI than the thoracic abnormality and/or the associated hydrops.

Care should be taken when interpreting our results. In our cohort, different techniques were used depending on 
different clinical factors and the indications for intervention varied. Therefore, our study group is relatively inhomogeneous and difficult to compare to other studies. Furthermore, the interpretation of our results is limited by the lack of an appropriate control group. It would be interesting to assess long-term neurodevelopment in all children who have had fetal hydrops, whether or not they received fetal therapy. The most important limitation is the relatively small sample size, which is inherent in the rarity of the disease and the fetal intervention. To reach reliable conclusions, large multicenter studies are warranted and an international web-based registry should be installed to prospectively gather outcome data in this high-risk group of children. It is important to continu- ously assess the neurodevelopment of the children, at fixed time points, e.g., at 2, 5, and 8 years, using standardized psychometric tests with increasing reliability of results with increasing age of the children. Only then, parents with a hydropic fetus with thoracic abnormalities can be accurately counselled including not only information on survival, but most importantly also reliable information on long-term outcome in case of survival.

\section{Disclosure Statement}

The authors declare that there is no conflict of interest.

\section{References}

1 Hagay Z, et al: Isolated fetal pleural effusion: a prenatal management dilemma. Obstet Gynecol 1993;81:147-152.

2 Bellini C, et al: Congenital fetal and neonatal visceral chylous effusions: neonatal chylothorax and chylous ascites revisited. A multicenter retrospective study. Lymphology 2012; 45:91-102.

3 Adzick NS, et al: Fetal lung lesions: management and outcome. Am J Obstet Gynecol 1998;179:884-889.

4 Rodeck $\mathrm{CH}$, et al: Long-term in utero drainage of fetal hydrothorax. N Engl J Med 1988; 319:1135-1138.

5 Picone $\mathrm{O}$, et al: Thoracoamniotic shunting for fetal pleural effusions with hydrops. Am J Obstet Gynecol 2004;191:2047-2050.

6 Yinon Y, Kelly E, Ryan G: Fetal pleural effusions. Best Pract Res Clin Obstet Gynaecol 2008;22:77-96.

7 Caserio S, et al: Congenital chylothorax: from foetal life to adolescence. Acta Paediatr 2010; 99:1571-1577.

8 Cavoretto P, et al: Prenatal diagnosis and outcome of echogenic fetal lung lesions. Ultrasound Obstet Gynecol 2008;32:769-783.

9 Deurloo KL, et al: Isolated fetal hydrothorax with hydrops: a systematic review of prenatal treatment options. Prenat Diagn 2007;27: 893-899.

10 Witlox RS, Lopriore E, Oepkes D: Prenatal interventions for fetal lung lesions. Prenat Diagn 2011;31:628-636.
11 Witlox RS, et al: Single-needle laser treatment with drainage of hydrothorax in fetal bronchopulmonary sequestration with hydrops. Ultrasound Obstet Gynecol 2009;34:355-357.

12 Touwen BC, Hempel MS, Westra LC: The development of crawling between 18 months and four years. Dev Med Child Neurol 1992; 34:410-416.

13 Bayley N: Bayley Scales of Infant and Toddler Development, ed 3. San Antonio, TX, Pearson Education, Inc., 2006.

14 Wechsler D: Wechsler Preschool and Primary Scale of Intelligence, ed 3 (WPPSI-III-NL). TX, The Psychological Corporation, 2002.

15 Wechsler D: Wechsler Intelligence Scale for Children, ed 3. TX, Psychological Corporation, 1991.

16 Surveillance of Cerebral Palsy in Europe: Surveillance of cerebral palsy in Europe: a collaboration of cerebral palsy surveys and registers. Surveillance of Cerebral Palsy in Europe (SCPE). Dev Med Child Neurol 2000;42:816824.

17 Palisano RJ, et al: Development and reliability of a system to classify gross motor function in children with cerebral palsy. Dev Med Child Neurol 1997;39:214-232.

18 Achenbach TM, Rescorla LA: Manual for the ASEBA Preschool Forms and Profiles. University of Vermont, Research Center for Children, Youth and Families, Burlington, VT, 2000 .
19 Verhulst FC, van der Ende J, Koot HM: Child Behavior Checklist (CBCL)/4-18 Manual. Rotterdam: Afdeling Kinder- en Jeugdpsychiatrie, Sophia Kinderziekenhuis/Academisch Ziekenhuis Rotterdam/Erasmus Universiteit Rotterdam, 1996

20 Witlox R, et al: Neonatal management and outcome after thoracoamniotic shunt placement for fetal hydrothorax. Arch Dis Child Fetal Neonatal Ed 2017, DOI: 10.1136/archdischild-2016-311265.

21 Lindenburg IT, et al: Long-term neurodevelopmental outcome after intrauterine transfusion for hemolytic disease of the fetus/newborn: the LOTUS study. Am J Obstet Gynecol 2011;206:141.e1-e8.

22 van Klink JM, et al: Long-term neurodevelopmental outcome after selective feticide in monochorionic pregnancies. Br J Obstet Gynaecol 2015;122:1517-1524.

23 van Klink JM, et al: Long-term neurodevelopmental outcome in survivors of twin-to-twin transfusion syndrome. Twin Res Hum Genet 2016;19:255-261.

24 Slaghekke F, et al: Neurodevelopmental outcome in twin anemia-polycythemia sequence after laser surgery for twin-twin transfusion syndrome. Ultrasound Obstet Gynecol 2014; 44:316-321.

25 van Klink JM, et al: Neurodevelopmental outcome at 2 years in twin-twin transfusion syndrome survivors randomized for the Solomon trial. Am J Obstet Gynecol 2016;214:113 e1e7. 